\title{
Efficacy of combination of aprepitant, ramosetron, and dexamethasone for chemotherapy-induced nausea and vomiting prevention in ovarian cancer patients
}

Min Kyu Kim¹ ${ }^{1}$, Chel Hun Choi², Jeong-Won Lee², Byoung-Gie Kim², Duk-Soo Bae²

${ }^{1}$ Department of Obstetrics and Gynecology, Samsung Changwon Hospital, Sungkyunkwan University School of Medicine, Hapsung-Dong, Masan Hoewon-Gu, Changwon, Republic of Korea

2Department of Obstetrics and Gynecology, Samsung Medical Center, Sungkyunkwan University School of Medicine, Seoul, Korea

\section{Purpose}

Women with ovarian carcinoma that are treated with paclitaxel/carboplatin are particularly susceptible to chemotherapyinduced nausea and vomiting (CINV). The current study evaluated the new combination (aprepitant/ramosetron/dexamethasone, $20 \mathrm{mg}$ ) in ovarian cancer patients receiving multiple cycles of paclitaxel/carboplatin.

\section{Method}

This is a prospective non-randomized single site study. Patients received the following regimen for the prevention of CINV-day 1 , $125 \mathrm{mg}$ aprepitant, $0.6 \mathrm{mg}$ ramosetron, and $20 \mathrm{mg}$ dexamethasone before chemotherapy; and days 2-3, $80 \mathrm{mg}$ aprepitant each day. The primary end point was the proportion of patients with complete response $(C R)$ during the $120 \mathrm{~h}$ following the first chemotherapy cycle. Toxicity assessments were conducted using the NCI-CTC investigator guide (version 3.0).

\section{Table 1. Patient characteristics at baseline}

\begin{tabular}{llr}
\hline Characteristics & No. of patients & Percent \\
\hline Total enrolled & 89 & 100 \\
Evaluable patients & 85 & \\
Site of primary disease & & 90.6 \\
$\quad$ Ovary & 77 & 9.4 \\
$\quad$ Tube & 8 & 100 \\
Chemotherapy regimen & & \\
$\quad$ Paclitaxel+carboplatin & 85 & \\
Age (years) & & \\
$\quad$ Median (range) & $55(28-88)$ & 25.9 \\
FIGO stage & & 61.2 \\
I and II & 22 & 12.9 \\
III & 52 & 81.2 \\
IV & 11 & 18.8 \\
Optimal debulking & & \\
$\quad$ Optimal & 69 & \\
$\quad$ Suboptimal & 16 & \\
\hline
\end{tabular}

Table 2. Percentage of patients reaching efficacy endpoints by phase in the first cycle

\begin{tabular}{llll}
\hline & $\begin{array}{l}\text { Acute phase } \\
(0-24 \mathrm{~h})\end{array}$ & $\begin{array}{l}\text { Delayed phase } \\
(24-120 \mathrm{~h})\end{array}$ & $\begin{array}{l}\text { Overall } \\
(0-120 \mathrm{~h})\end{array}$ \\
\hline Total no. of patients & 85 & 85 & 85 \\
No emesis (no. (\%)) & $84(98.8)$ & $81(95.3)$ & $81(95.3)$ \\
No rescue (no. (\%)) & $85(100)$ & $78(91.8)$ & $78(91.8)$ \\
Complete response (\%) & $84(98.8)$ & $76(89.4)$ & $76(89.4)$ \\
\hline
\end{tabular}

Table 3 Probability of complete responses by chemotherapy cycle

\begin{tabular}{lccccccc}
\hline & Cycle & Cycle & Cycle & Cycle & Cycle & Cycle \\
& 1 & 2 & 3 & \multicolumn{1}{l}{4} & \multicolumn{1}{l}{5} & \multicolumn{1}{l}{6} \\
\hline $\begin{array}{l}\text { Estimated probability of } \\
\quad \text { complete response (\%) }\end{array}$ & 89.4 & 85.9 & 84.4 & 82.6 & 84.6 & 82.8 \\
$\begin{array}{l}\text { No. of patients in cycle } \\
\text { a }\end{array}$ & 85 & 78 & 77 & 69 & 65 & 64 \\
$\begin{array}{l}\text { No. of patients with } \\
\quad \text { complete response }\end{array}$ & 76 & 67 & 65 & 57 & 55 & 53 \\
$\begin{array}{l}\text { No. of failures } \\
\text { No. of withdrawals }\end{array}$ & 9 & 11 & 12 & 12 & 10 & 11 \\
\hline
\end{tabular}

Table 4. Nausea results for cycles 1-6

\begin{tabular}{llll}
\hline Characteristics & $\begin{array}{l}\text { No. of } \\
\text { patients }\end{array}$ & $\begin{array}{l}\text { No nausea } \\
(\%)\end{array}$ & $\begin{array}{l}\text { No significant } \\
\text { nausea (\%) }\end{array}$ \\
\hline Cycle 1 & 85 & $51(60.0)$ & $74(87.1)$ \\
Cycle 2 & 78 & $50(64.1)$ & $63(80.8)$ \\
Cycle 3 & 77 & $46(59.7)$ & $63(81.8)$ \\
Cycle 4 & 69 & $37(53.6)$ & $55(79.7)$ \\
Cycle 5 & 65 & $36(55.4)$ & $51(78.5)$ \\
Cycle 6 & 64 & $35(54.7)$ & $53(82.8)$ \\
\hline
\end{tabular}

Table 5. Summary of adverse events for cycles 1-6 $(n=460$ cycles).

\begin{tabular}{ll}
\hline Characteristics & Cycles 1-6 (\%) \\
\hline Febrile neutropenia & $2(0.4)$ \\
Infection & $4(0.9)$ \\
Anorexia & $27(5.9)$ \\
Fatigue & $47(10.2)$ \\
Constipation & $57(12.4)$ \\
Diarrhea & $39(8.5)$ \\
Headache & $51(11.1)$ \\
Grade 3 or 4 hematologic toxicities & \\
$\quad$ Neutropenia & $18(3.9)$ \\
$\quad$ Anemia & $4(0.9)$ \\
Thrombocytopenia & $6(1.3)$ \\
AST/ALT & $2(0.4)$ \\
$\quad$ Renal & $0(0)$ \\
Clinically adverse events & \\
$\geq 1$ adverse events & $179(38.9)$ \\
Drug-related adverse events & $35(7.6)$ \\
Serious adverse events & $10(2.2)$ \\
Discontinued because of adverse events & $0(0)$ \\
\hline
\end{tabular}

Based on the National Cancer Institute's Common Toxicity Criteria

${ }^{\text {a }}$ Adverse events that were considered by the investigators to be likely or definitely related to the study drug

\section{Results}

Of the 89 patients enrolled, 85 patients were evaluable for efficacy and toxicity, and $68(80 \%)$ completed all 6 cycles. In cycle 1, the percentage of patients who achieved CR in the acute, delayed, and overall phases was $98.8 \%, 89.4 \%$, and $89.4 \%$, respectively. Of the 460 cycles, adverse events, drugrelated adverse events, and serious adverse events occurred in 179 (38.9\%), 35 (7.6\%), and 10 cycles (2.2\%), respectively. The most common adverse event was constipation (12.4\%) and headache (11.1\%). None of the patients discontinued the study because of adverse events.

\section{Conclusion}

The combination of aprepitant, ramosetron, and high-dose dexamethasone demonstrated efficacy for CINV prevention in ovarian cancer patients receiving paclitaxel and carboplatin. 